\section{INTRATUMORAL ADMINISTRATION OF ALUM-TETHERED ENGINEERED INFLAMMATORY CYTOKINES SAFELY ELICITS POTENT LOCAL AND SYSTEMIC IMMUNITY}

Yash Agarwal* ${ }^{*}$ K. Wittrup, Darrell Irvine. Massachusetts Institute of Technology, Cambridge, MA, United States

Background While immune checkpoint blockade therapy has improved progression-free survival in patients suffering from cancer over other treatments, ${ }^{1-4}$ these typically elicit durable responses in only minority of patients, in part because of the highly immunosuppressive tumor microenvironment (TME). ${ }^{5} 6$ Rational combinations with inflammatory cytokines can relieve some immunosuppression, ${ }^{7}$ but systemic dosing of these proteins is impeded by severe immune-related adverse events (irAE). ${ }^{9-14}$ One approach to focus the activity of immunostimulatory agents in tumors while lowering systemic toxicity is to administer these drugs intratumorally. However, intratumoral injection alone generally achieves limited persistence in the TME, as drugs quickly clear from the tumor via lymphatics and the tumor vasculature, rapidly leading to harmful accumulation in the circulation. ${ }^{15} 16$ Thus, approaches to promote in vivo retention of intratumorally administered drugs are necessary to maximize local stimulation.

Methods We engineered Interleukin-12 (IL-12) with a peptide tag containing multiple phosphoserine (pSer) residues, through in-cell phosphorylation during recombinant expression in mammalian cells. We then inoculated mice with B16F10, or Ag104A tumors, treated established tumors intratumorally with a single dose of IL-12 mixed with alum, and monitored the tumor size and weights over time. Immunophenotyping of tumors and draining lymph nodes (dLNs) was conducted at several timepoints after treatment. Tumors and serum were also collected to perform bead-based Luminex analysis of many cytokines (including IL-12 and IFN- $\gamma$ ).

Results Cytokines with pSer tags bind tightly to the common vaccine adjuvant aluminum hydroxide (alum) via ligand exchange $(72 \%$ pSer-IL-12 vs 3.5\% IL-12, P<0.0001). Alum particles form a physical depot at injection sites that is persistent over weeks. So, intratumoral injection of pSer-IL-12loaded alum led to $>400$-fold greater retention of protein relative to unanchored pSer-IL-12 with 2-fold lower serum ALT (a biomarker for IL-12 systemic toxicity). Further, a single dose of alum-tethered pSer-IL-12 induced 5-fold greater IFN- $\gamma$ secretion $(\mathrm{P}=0.0031)$ at the tumor primarily by $\mathrm{CD} 8+\mathrm{T}$ cells and doubled $(\mathrm{P}<0.0001)$ the proportion of tumor antigen-carrying, CD86-expressing CD103+ DCs in dLN relative to free IL-12. Further, intratumoral alum/pSer-IL-12 therapy enhanced responses to checkpoint blockade (anti-PD1), leading to a cure rate of $52 \%$ in poorly immunogenic B16F10 tumors compared to $0 \%$ for free IL-12. Local intratumoral treatment of ipsilateral tumors in mice also led to clearance of large, untreated contralateral tumors in $9 / 15$ animals for alum/pSerIL-12 vs. 5/17 animals for unanchored IL-12 ( $\mathrm{P}=0.04)$.

Conclusions Thus, intratumoral treatment with alum-anchored cytokines presents a safe, tumor-agnostic approach to improve local and systemic anti-cancer immunity.

\section{REFERENCES}

1. Wolchok JD, Chiarion-Sileni V, Gonzalez R, Rutkowski P, Grob JJ, Cowey CL, et al. Overall survival with combined nivolumab and ipilimumab in advanced melanoma. New England Journal of Medicine 2017;377(14):1345-56.

2. Ansell SM, Lesokhin AM, Borrello I, Halwani A, Scott EC, Gutierrez M, et al. PD1 Blockade with nivolumab in relapsed or refractory Hodgkin's lymphoma. New England Journal of Medicine [Internet]. 2015;372(4):311-9. Available from: http://www.nejm.org/doi/10.1056/NEJMoa1411087.
3. Brahmer J, Reckamp KL, Baas P, Crinò L, Eberhardt WEE, Poddubskaya E, et al. Nivolumab versus docetaxel in advanced squamous-cell non-small-cell lung cancer. New England Journal of Medicine [Internet]. 2015;373(2):123-35. Available from: http://www.nejm.org/doi/10.1056/NEJMoa1504627.

4. Bellmunt J, de Wit R, Vaughn DJ, Fradet Y, Lee J-L, Fong L, et al. Pembrolizumab as second-line therapy for advanced urothelial carcinoma. New England Journal of Medicine [Internet]. 2017;376(11):1015-26. Available from: http://www.nejm. org/doi/10.1056/NEJMoa1613683

5. Yi M, Jiao D, Xu H, Liu Q, Zhao W, Han $X$, et al. Biomarkers for predicting efficacy of PD-1/PD-L1 inhibitors [Internet]. Vol. 17, Molecular Cancer. BioMed Central Ltd.; 2018 [cited 2021 May 2]. p. 1-14. Available from: https://doi.org/ 10.1186/s12943-018-0864-3

6. Anderson KG, Stromnes IM, Greenberg PD. Obstacles posed by the tumor microenvironment to T cell activity: a case for synergistic therapies [Internet]. Vol. 31 , Cancer Cell. Cell Press; 2017 [cited 2021 May 2]. p. 311-25. Available from: https://pubmed.ncbi.nlm.nih.gov/28292435/.

7. Smyth MJ, Ngiow SF, Ribas A, Teng MWL. Combination cancer immunotherapies tailored to the tumour microenvironment [Internet]. Vol. 13, Nature Reviews Clinical Oncology. Nature Publishing Group; 2016;143-58. Available from: https:// pubmed.ncbi.nlm.nih.gov/26598942/.

8. Moynihan KD, Opel CF, Szeto GL, Tzeng A, Zhu EF, Engreitz JM, et al. Eradication of large established tumors in mice by combination immunotherapy that engages innate and adaptive immune responses. Nature Medicine 2016;22 (12):1402-10.

9. Milling L, Zhang Y, Irvine DJ. Delivering safer immunotherapies for cancer Advanced Drug Delivery Reviews [Internet]. 2017;114:79-101. Available from: http://dx.doi.org/10.1016/j.addr.2017.05.011

10. Lasek W, Zagożdżon R, Jakobisiak M. Interleukin 12: still a promising candidate for tumor immunotherapy? Cancer Immunology, Immunotherapy 2014;63(5):41935

11. Kirchner GI, Franzke A, Buer J, Beil W, Probst-Kepper M, Wittke F, et al. Pharmacokinetics of recombinant human interleukin-2 in advanced renal cell carcinoma patients following subcutaneous application. British Journal of Clinical Pharmacology [Internet] 1998;46(1):5-10. Available from: /pmc/articles/PMC1873983/.

12. June $\mathrm{CH}$, Warshauer JT, Bluestone JA. Is autoimmunity the Achilles' heel of cancer immunotherapy? Nature Medicine [Internet] 2017;23(5):540-7. Available from: http://www.nature.com/articles/nm.4321

13. Leonard JP, Sherman ML, Fisher GL, Buchanan $\sqcup$, Larsen G, Atkins MB, Sosman $J A$, Dutcher JP, Vogelzang JLR. Effects of single-dose interleukin-12 exposure on interleukin-12-Associated toxicity and interferon- $\gamma$ Production. Blood 1997;2541-

14. Atkins MB, Robertson MJ, Gordon M, Lotze MT, DeCoste M, DuBois JS, et al. Phase I evaluation of intravenous recombinant human interleukin 12 in patients with advanced malignancies. Clinical Cancer Research 1997;3(3).

15. van Herpen CML, van der Voort $R$, van der Laak JAWM, Klasen IS, de Graaf AO, van Kempen LCL, et al. Intratumoral rhlL-12 administration in head and neck squamous cell carcinoma patients induces B cell activation. International Journal of Cancer [Internet] 2008;123(10):2354-61. Available from: https://pubmed.ncbi. nlm.nih.gov/18729197/.

16. Pfreundschuh MG, Tilman Steinmetz $H$, Tüschen $R$, Schenk V, Diehl V, Schaadt M. Phase I study of intratumoral application of recombinant human tumor necrosis factor. European Journal of Cancer and Clinical Oncology [Internet] 1989;25(2). Available from: https://pubmed.ncbi.nlm.nih.gov/2702990/

Ethics Approval All animal studies and procedures were carried out following federal, state and local guidelines under an institutional animal care and use committee-approved animal protocol (Protocol no. 0720-070-23) by the Committee of Animal Care at MIT.

http://dx.doi.org/10.1136/jitc-2021-SITC2021.738 